\title{
A cross-national diagnosis of infodemics: comparing the topical and temporal features of misinformation around COVID-19 in China, India, the US, Germany and France
}

Zeng, Jing ; Chan, Chung-Hong

\begin{abstract}
This study empirically investigates how the COVID-infodemic manifests differently in different languages and in different countries. This paper focuses on the topical and temporal features of misinformation related to COVID-19 in five countries. COVID-related misinformation was retrieved from 4,487 fact-checked articles. A novel approach to conducting cross-lingual topic extraction was applied. The rectr algorithm, empowered by aligned word-embedding, was utilised. To examine how the COVID-infodemic interplays with the pandemic, a time series analysis was used to construct and compare their temporal development. The crosslingual topic model findings reveal the topical characteristics of each country. On an aggregated level, health misinformation represents only a small portion of the COVID-infodemic. The time series results indicate that, for most countries, the infodemic curve fluctuates with the epidemic curve. In this study, this form of infodemic is referred to as "point-source infodemic". The second type of infodemic is continuous infodemic, which is seen in India and the United States (US). In those two countries, the infodemic is predominantly caused by political misinformation; its temporal distribution appears to be largely unrelated to the epidemic development. Despite the growing attention given to misinformation research, existing scholarship is dominated by single-country or mono-lingual research. This study takes a cross-national and cross-lingual comparative approach to investigate the problem of online misinformation. This paper demonstrates how the technological barrier of cross-lingual topic analysis can be overcome with aligned word-embedding algorithms.
\end{abstract}

DOI: https://doi.org/10.1108/OIR-09-2020-0417

Posted at the Zurich Open Repository and Archive, University of Zurich

ZORA URL: https://doi.org/10.5167/uzh-199058

Journal Article

Accepted Version

Originally published at:

Zeng, Jing; Chan, Chung-Hong (2021). A cross-national diagnosis of infodemics: comparing the topical and temporal features of misinformation around COVID-19 in China, India, the US, Germany and France. Online Information Review, 45(4):709-728.

DOI: https://doi.org/10.1108/OIR-09-2020-0417 
This is the Author Accepted Manuscript (AAM) of the article accepted by Online Information Review.

Corresponding author: Jing Zeng (j.zeng@ikmz.uzh.ch) 


\title{
A cross-national diagnosis of infodemics: Comparing the topical and temporal features of misinformation around COVID-19 in China, India, the US, Germany and France
}

\author{
Jing Zeng \\ University of Zurich, Switzerland \\ Chung-hong Chan \\ University of Mannheim, Germany
}

\begin{abstract}
Purpose: This study empirically investigates how the COVID-infodemic manifests differently in different languages and in different countries. This paper focuses on the topical and temporal features of misinformation related to COVID-19 in five countries.

Design/methodology/approach: COVID-related misinformation was retrieved from 4487 factchecked articles. A novel approach to conducting cross-lingual topic extraction was applied. The rectr algorithm, empowered by aligned word-embedding, was utilised. To examine how the COVIDinfodemic interplays with the pandemic, a time series analysis was used to construct and compare their temporal development.

Findings: The cross-lingual topic model findings reveal the topical characteristics of each country. On an aggregated level, health misinformation represents only a small portion of the COVID-infodemic. The time series results indicate that, for most countries, the infodemic curve fluctuates with the epidemic curve. In this study, this form of infodemic is referred to as 'point-source infodemic'. The second type of infodemic is continuous infodemic, which is seen in India and the United States (US). In those two countries, the infodemic is predominantly caused by political misinformation; its temporal distribution appears to be largely unrelated to the epidemic development.

Originality: Despite the growing attention given to misinformation research, existing scholarship is dominated by single-country or mono-lingual research. This study takes a cross-national and crosslingual comparative approach to investigate the problem of online misinformation. This paper demonstrates how the technological barrier of cross-lingual topic analysis can be overcome with aligned word-embedding algorithms.
\end{abstract}

Keywords COVID-19, misinformation, cross-lingual topic modelling

Paper Type: Research paper

\section{Introduction}

Since its beginning in China in December 2019, the COVID-19 pandemic has been plagued by misinformation, disinformation and conspiracy theories (Brennen et al., 2020; Bruns et al., 2020; Smith et al., 2020). In February 2020, the Director-General of the World Health Organization (WHO) pointed out that misinformation was spreading faster than the virus, and that the world is fighting both the pandemic and an 'infodemic'. According to WHO, the term, infodemic, refers to an 'excessive amount of information about a problem, making it difficult to identify a solution. They (infodemics) can spread misinformation, disinformation and rumours during a health emergency' (United Nations, 2020). These 
forms of information can hamper public health responses, establish distrust among the public and ultimately lead to deadly consequences.

Although the danger of misinformation is an issue of global relevance, most previous studies have deployed a monolingual or single-country approach (Humprecht et al., 2020), with a particular focus on English-language materials or English-speaking regions. This lack of accumulated and comparative perspective makes it difficult to assess national characteristics in infomedics and identify its remedies. There is no single-country strategy that can simply and neatly cure the global misinformation epidemic. Explanations for and effective methods to stem the infodemic tide that is surging across the globe require a deeper understanding of the domestic political, economic and cultural climates of different countries (Chandler et al., 2015; Gray, 2008; Uscinski, 2019).

This study introduces an innovative approach to investigating the development of the COVIDinfodemic with a cross-national and multilingual comparative perspective. Focusing on debunked misinformation in Chinese, French, German and English, we examine how the COVID-infomedic is unfolding differently in China, the United States (US,) India, Germany and France. A corpus of 4487 COVID-related misinformation articles was built through sourcing Google's Fact Check Explorer API and China's national rumour-debunking platform. Misinformation included in the corpus was circulated online and debunked between January and July 2020. This study applied a new multilingual topicmodelling algorithm — rectr (Chan et al., 2020) - as well as a time series analysis, to explore how the COVID-infodemic manifests differently in different countries.

\section{Literature Review}

\section{Conceptual approach to misinformation}

In both media and academic research, the phenomenon of misinformation has been discussed with various degrees of conceptual fuzziness (DiFonzo and Bordia, 2007; Rojecki and Meraz, 2016). For instance, it is not uncommon to see 'misinformation' being used interchangeably with terms, such as 'disinformation', 'rumour' or 'fake news'. At the same time, scholars have attempted to conceptually clarify various forms of potentially false information (see DiFonzo and Bordia, 2007; Wardle and Derakhshan, 2017).

The use of these terms also varies depending on the cultural context. For instance, in the Chinese language, the term for rumour-yaoyan (谣言) —is often used to refer to a wide range of (potentially) false information, serving a similar function as 'misinformation' in the English language. Although most of the Chinese data included in this study are described as 'rumour' in the Chinese language, for the purpose of this study, we refer to all forms of false information as misinformation.

In this study, we define misinformation as a form of claim whose falsity is verifiable and has been confirmed. It is worth noting that the content described as misinformation in this article can have a conceptual overlap with conspiracy theories, false rumour, fake news, propaganda or disinformation ${ }^{1}$. In the following section, we draw upon theories from social psychological accounts of misinformation to discuss the social function of misinformation, especially in the context of health crises.

The social function of misinformation is most clearly articulated in the field of social psychology (Allport and Postman, 1947; DiFonzo and Bordia, 2007; Shibutani, 1966), wherein the communication of misinformation is most commonly perceived as a form of collective sense-making through which people 'restore a sense of meaning and a semblance of control within the context of an unfamiliar and anxious situation' (DiFonzo and Bordia, p. 331). The sense-making function of misinformation determines that it arises and flourishes in contexts that are ambiguous or potentially threatening. Crisis events are often characterised by a paucity of information and a state of anxiety

\footnotetext{
${ }^{1}$ To see the conceptual differentiation between these terms, refer to Guess and Lyon (2020) and Zeng (forthcoming).
} 
among the populace, so these occurrences are particularly susceptible to the dissemination of false information.

In addition to sense-making, another primary social function of misinformation is to undermine outgroups or rivals. Disinformation and wedge-driving rumours are the two most direct manifestations of this function. Disinformation can be defined as deliberately deceptive and propagated information, which is used purposefully to undermine public support of a rival body (Lewandowsky et al., 2013; Karlova and Fisher, 2013). For instance, in recent literature, a rich body of research has been conducted to investigate disinformation campaigns in the US presidential elections (Marwick and Lewis, 2017; Ross and Rivers, 2018). Wedge-driving rumours are unverified claims that are used to put other groups down (Knapp, 1944). For instance, Allport and Postman's (1947) classic work on rumour in the US documented how false claims that black servants were using the 'lady of the house's' comb were propagated among certain white people to defend the collective 'white' identity.

These aforementioned social and political dynamics of misinformation also mean that its construction and circulation are highly contextual. As Foucault (1980) stated, 'each society has its regime of truth, its general politics of truth' (p. 132).

\section{Misinformation and public health crises}

From water fluoridation conspiracy theories (Newbrun, 1996) to the anti-vaccination movement (Kata, 2012), from pseudoscience-driven HIV stigma (Herek et al., 2002) to the latest 'Corona-racism' (Abidin and Zeng, 2020), there is mounting evidence demonstrating how health misinformation can hinder public health efforts and adversely affect peoples' lives.

In comparison to other public health issues, epidemics are particularly susceptible to the impacts of misinformation. For instance, amidst the 2014-2016 Ebola outbreak, numerous widely circulated alternative treatments were documented, ranging from blood injections to salt water and nanosilver consumption (Fung et al., 2016; Oyeyemi et al., 2014). Following the 2015 Zika outbreak, conspiracy theories claiming that the Zika virus was a bioweapon (Wood, 2018) and pseudo-scientific claims about the Zika vaccine (Dredze et al., 2016) were broadly disseminated.

The susceptibility of epidemics to misinformation partially stems from their intrinsic characteristics. Epidemics, especially those caused by novel viruses, are often accompanied by uncertainties around their origin, transmission and cure. As discussed in the previous section, these circumstances foster the circulation of misinformation, which serves as a sense-making mechanism.

In comparison to other forms of uncertain crises (such as natural disasters, terrorist attacks) misinformation debunking around epidemics can also be hampered by insufficient health literacy, which can be defined as 'the degree to which people have the capacity to obtain, process, and understand basic health information and services needed to make appropriate health decisions' (Parker et al., 2013, p. 147). When official medical advice is perceived as black boxed or incompatible with local customs (Chandler et al., 2015), individuals may turn to easy-to-digest pseudoscience as an alternative.

If an epidemic is a catalyst for the spread of misinformation, then a pandemic is a veritable hotbed. During a pandemic, the complexity of the information ecosystem scales up, with more diverse actors and falsifications emerging. More importantly, an infodemic can be further exacerbated by crossnational geopolitical tensions. During the current COVID health crisis, there has been clear evidence that the crisis is weaponised for political purposes. The Sino-US war of words over the pandemic is a case in point. Throughout the pandemic, President Trump has repeatedly and openly encouraged and promulgated inaccurate/false medical information and conspiracy theories (Dale, 2020). Some examples are his public embracing of hydroxychloroquine as an effective treatment despite scientific evidence to the contrary as well as entertaining unfounded claims that COVID-19 originated in a Chinese laboratory. At the same time, the Chinese government was accused of promoting the equally groundless claim that the new coronavirus originated in the US (Sardarizadeh and Robinson, 2020). 
Misinformation during epidemics is not merely prevalent; it also has significant consequences, hinders efforts to control the epidemic (Allgaier and Svalastog, 2015) and, in some cases, results in death (Spring, 2020). However, when the falsification of a health crisis becomes a global issue-a misinformation pandemic - more contextual understanding and localised remedies are required.

Both a theoretical review of the social function of misinformation and empirical evidence from health communication research indicates the importance of contextual particularities in understanding infodemics. Cross-lingual and cross-national comparative perspectives are urgently required. However, as previously mentioned, existing academic accounts of misinformation are dominated by singlecountry and monolingual research. As one of the handful of studies seeking to systematically investigate the phenomenon of misinformation on a cross-national level, Humprecht et al.'s (2020) research illustrates how countries' vulnerability and resistance to misinformation is shaped by their political and media landscapes. Empirical evidence from prior health communication research also suggests how the socio-political context shapes the scope of misinformation during health crises (Chandler et al., 2015; Fung et al., 2016).

To contribute to the scarce but emerging academic efforts to generate accumulated evidence in cross-country particularities in misinformation communication, this study compares the topical and temporal features of the COVID-infodemic in four countries with distinctive political and media systems. Two empirical research questions were asked:

RQ1: What are the topical features of the COVID-infodemic in China, India, the US, Germany and France?

RQ2: What are the temporal features of the COVID-infodemic in China, India, the US, Germany and France?

The rationale of our focus on the topical and temporal features is to identify the key areas of controversial issues and to explore how these issues evolve with the pandemic. In the context of the current unfolding COVID-infodemic, these questions are key to effectively mitigating the adverse effects of misinformation. After all, unlike an epidemic, there is no 'universal cure' for an infodemic. Instead, counterstrategies to COVID-related information should be contingent and responsive to the actual development of the health crisis.

\section{Data and Methodology}

\section{Data collection}

In existing misinformation research, scholars commonly use fact-checking or rumour-debunking archives to study misinformation topics around a controversial event (Arif et al., 2016; Yang et al., 2012; Zeng et al., 2017). In more recent literature, similar approaches have also been applied to investigate misinformation topics around COVID-19 (Elhadad and Gebali, 2020; Shahi and Nandini, 2020). Following suit, we constructed our corpus to study misinformation related to COVID-19. For Chinese rumour-debunking, we used a web-crawler to scrape all Chinese rumour debunking articles from the COVID-19 section under China's national rumour-debunking platform: 中国互联网联合辟 谣本台 ${ }^{2}$. This platform aggregates rumour-debunking messages from fact-check services in China. For the non-Chinese content, we employed Google Fact Check Explorer API, a search engine that allows users to fact check information using keywords. We used Fact Check Explorer's API to retrieve

${ }^{2}$ http://www.piyao.org.cn/2020yqpy/ 
debunking articles about COVID-19 using the keywords: 'COVID-19' and 'coronavirus' ${ }^{3}$. Content from Fact Check Explorer was collected in three languages: English, German and French ${ }^{4}$.

\section{Data pre-processing}

In total, 4487 articles were collected from the two aforementioned sources. The earliest and the latest publication dates of all the articles are 22-01-2020 and 28-07-2020, respectively. There were many duplicates in the collected articles. The R package textsdc offers a text deduplication algorithm based on cosine similarity. Using that algorithm, 3633 unique articles were retained. Of those, the percentages of articles written in English, Chinese, French and German are 66.4\%, 20.6\%, 7.5\% and 5.5\%, respectively.

We classified articles by the hosting country of the organisation. For example, a rumour debunking article published by Agence France-Presse was classified as France, by Deutsche PresseAgentur as Germany and by Xinhua as China. The top five hosting countries, in terms of number of debunking articles, are India (22.5\%), China (20.6\%), the US (19.7\%), France (17.3\%) and Germany $(5.9 \%)$ (Figure 1). In the following analysis, we focus on these five countries.

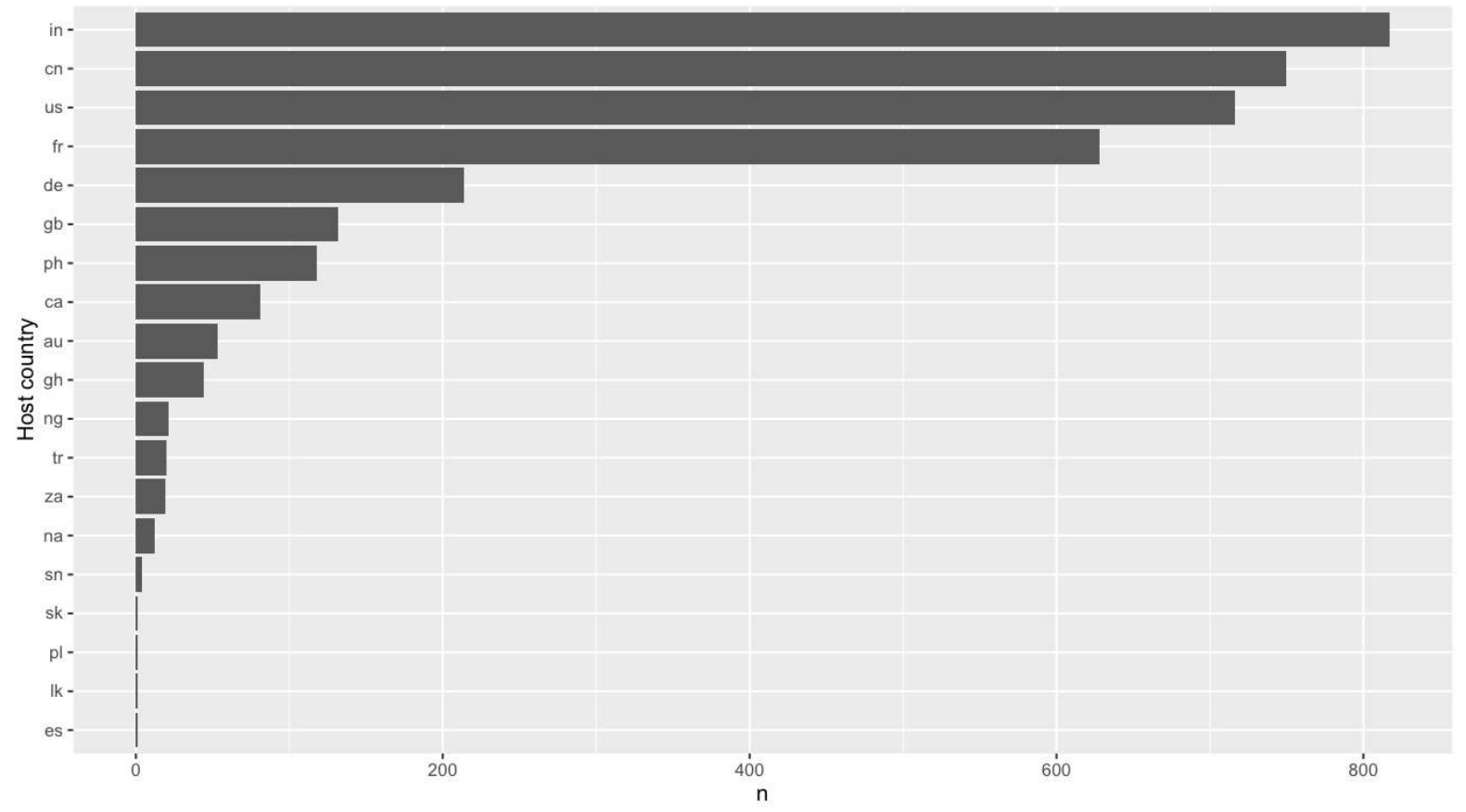

Figure 1: Regional distribution of the rumour debunking articles

\section{Cross-lingual topic model}

In this study, we used a two-step approach to extract and analyse topics in the corpus. As the first step, a cross-lingual topic model was utilised to extract the topics of the 3633 unique articles. A cross-lingual topic in a multilingual corpus refers to a topic that can be jointly compared across languages (Chan $e t$ al., 2020; Zhang et al., 2010). As previously mentioned, our data consists of four different languages:

\footnotetext{
${ }^{3}$ Because the term, COVID-19, was only introduced on 11 February 2020, our data collection also used 'coronavirus' to target content published before WHO's introduction of the new name.

${ }^{4}$ The main consideration for our language selection is the authors' ability to interpret the topic model results. Although our cross-lingual topic extraction algorithm is able to extract topics from many more languages, in-depth and meaningful results still require human interpretation. Considering the language skills of the authors, only four languages were chosen for this study.
} 
English, German, French and Chinese. A cross-lingual topic model allows us to directly compare the topical similarity between two articles in these languages without translation.

Traditional topic modelling techniques, such as Latent Dirichlet Allocation (LDA), cannot be used to extract cross-lingual topics without machine translation. As Chan et al., (2010) pointed out, methods relying on machine translation (e.g. Google Translate) are unreproducible and not costeffective. Alternatively, Chan et al. (2020) introduced an algorithm: The Reproducible Extraction of Cross-lingual Topic using R (rectr). Rectr is a cross-lingual topic modelling method based on the pretrained language model M-BERT. Using rectr to extract cross-lingual topics consists of five steps: (1) obtaining aligned word embeddings, (2) creating a document-feature matrix, (3) cleaning up systematic language differences and (4) training a topic model. A more detailed explanation of each of these steps with examples is available in Chan et al. (2020).

We followed the steps proposed by Chan et al. (2020) to extract cross-lingual topics from our multilingual articles, and we reported a topical probability vector $\left(\theta_{t}\right)$ for each article. Through qualitative reading of the sample articles with high theta, two coders manually annotated all the crosslingual topics identified by rectr. In the second step, we further aggregated the topics identified through the first step into two categories. This step facilitated the following time series analysis.

Based on our earlier discussion of the social functions of misinformation and empirical findings from health communication research, we proposed to conceptually and analytically approach COVIDrelated misinformation by distinguishing between health misinformation and non-health misinformation. The distinction is based on DiFonzo and Bordia's (2007) conceptual framework, which was originally applied to rumour and other related concepts by examining their content, function and context. This categorisation serves the following time series analysis.

We labelled the first category of misinformation as health misinformation, which includes false claims about the scientific and medical aspects of the pandemic. This type of misinformation mainly manifests as the first social function of misinformation: sense-making. As previously explained, the current pandemic, as well as epidemics in general, is uncertain and threatening. In these contexts, misinformation arises as a by-product of crises, relatively independent of social-political events. In terms of temporal development, this group of misinformation fluctuates closely with the ebb and flow of the epidemic development.

We labelled the second type of misinformation as non-health misinformation; claims under this group are dominated by political rumours, disinformation and conspiracy theories. This category of misinformation reflects the second social function of misinformation: to undermine outgroups or rivals. Unlike misinformation that focuses on sense-making, misinformation in this group takes advantage of the health crisis, stirring political/societal tensions. In terms of temporal development, non-health misinformation is more sensitive to political events than health misinformation.

Table 1. Binary classification of misinformation related to Covid-19 by function, content characteristic and context

\begin{tabular}{|c|c|c|}
\hline & Health misinformation & Non-health misinformation \\
\hline Function & $\begin{array}{l}\text { Making sense of the health crisis, a by- } \\
\text { product of crises, independent from } \\
\text { social-political events }\end{array}$ & $\begin{array}{l}\text { Taking advantage of the health crisis, stirring } \\
\text { political and societal tensions }\end{array}$ \\
\hline $\begin{array}{l}\text { Content } \\
\text { characteristic }\end{array}$ & $\begin{array}{l}\text { Factually wrong, medical } \\
\text { misinformation (e.g. how it is } \\
\text { transmitted, cure, treatment) }\end{array}$ & $\begin{array}{l}\text { Politically-driven fabricated claims, e.g. } \\
\text { conspiracy theories, wedge-driving rumours } \\
\text { attacking out-groups or criticising political } \\
\text { actors }\end{array}$ \\
\hline Context & $\begin{array}{l}\text { Emerges and evolves with the } \\
\text { epidemic development }\end{array}$ & $\begin{array}{l}\text { Emerges during the health crisis, but its } \\
\text { fluctuation is relatively independent of the } \\
\text { epidemic situation }\end{array}$ \\
\hline
\end{tabular}


As previously discussed, different types of misinformation operate differently, and for different reasons. Many prior manual-coding based analyses of COVID-misinformation have provided more thorough content-based categories (e.g. Brennen et al., 2020). In comparison, our binary categorisation is more streamlined; it can capture the most important nuance of COVID-related misinformation. It is worth noticing that, as a study deploying automatic cross-lingual topic modelling, this step of further grouping topics does not aim to contribute a conceptual understanding of misinformation functions; rather, it serves analytical purposes. The rationale for differentiating two types of misinformation is simply to better interpret the temporal development of automatically identified topics.

\section{Time series analysis: Constructing the infodemic curve}

An epidemic curve has long been used as a statistical chart to track the different phases of an epidemic (Rosenberg, 2014). The x-axis of an epidemic curve displays the date of the disease onset and the $y$ axis displays the total number of new cases. From a public health standpoint, the y-axis usually displays the total number of new cases detected and treated by public health facilities (e.g. screening stations, hospitals, clinics etc.). When the at-risk population is fixed (e.g. the total population of a country), the curve essentially displays the daily incidence of the disease. We used the data published by the European Centre for Disease Prevention and Control (ECDC) to build a time series of confirmed cases in China, Germany, France, India and the US ${ }^{5}$.

Applying the same concept, it is possible to track an infodemic using the same curve. We named this curve the infodemic curve - it displays essentially the same information as the epidemic curve. However, the y-axis displays the total amount of misinformation detected and debunked by factcheckers. Therefore, fact-checkers play the same role as the public health facilities in the case of an epidemic to seek, diagnose and treat misinformation by fact-checking. To compare the two curves, we normalised them by min-max transformation; i.e. the values in the two curves have a range of [0-1].

Following the automated cross-lingual extraction of topics in COVID-19 misinformation, two coders further grouped the identified topics into health misinformation and non-health misinformation. As noted in the previous section, these two types of misinformation operate differently and are expected to have different interactions with the development of the epidemic in each country.

As stated in the previous section, we anticipated that health misinformation is sensitive to the development of the COVID-epidemic. To restate this in time series terms, we anticipated that the epidemic is a Granger cause of the infodemic curve of medical misinformation, i.e. the past value of the information from the epidemic curve is predictive of the current value of the infodemic curve. This can be studied by vector autoregression (VAR). An elaborate explanation of VAR is available from Wells et al. (2019). VAR models how previous values from both the dependent and independent variables as a time series can predict the current value of both the dependent and independent variables. This analysis reveals the possible temporal precedence of a time series and the mutual influence between multiple time series. The temporal precedence of epidemic over infodemic can be tested by a Granger causality test of the VAR model. The R package vars (Pfaff, 2008) was used for this analysis.

\section{Results}

\section{Topical distribution}

Our cross-lingual topic model extracts eight cross-lingual topics, which are presented in Table 2, with example claims. Based on the working definition provided in the Methods section, these eight topics were then aggregated into health misinformation and non-health misinformation. The provided

\footnotetext{
${ }^{5}$ The open-access data were downloaded from Our World in Data (Ritchie, 2020) on 3 September 2020.
} 
description and categorisation were agreed upon by two authors, who first independently annotated all eight topics then discussed the results (Maier et al., 2018). For each article, we assigned a best-fit topic based on the highest theta from our rectr model.

Amongst the eight identified topics, three were categorised as health misinformation. Content under this category includes vaccine and treatment (topic 2), transmission and prevention (topic 6) and testing (topic 8). In total, 1233 articles (33.9\%) from our dataset are related to these topics. Five topics were categorised as non-health misinformation, which include false claims about the origin and severity of the pandemic (topic 1), fabricated content about the responses of politicians and authorities to the crisis (topic 3), inaccurate information related to educational policies and children in general (topic 4), conspiracy theories and disinformation (topic 5) and inaccurate reports regarding traveling restrictions (topic 7). This group of misinformation was found in 2400 articles $(66.1 \%)$ in the dataset.

Table 2. Topic explanation, categorisation and examples

\begin{tabular}{|c|c|c|c|c|}
\hline Topic & Description & Category & Example of false claims & $\begin{array}{l}\text { Number of } \\
\text { best-fitted } \\
\text { articles }(\%)\end{array}$ \\
\hline 1 & $\begin{array}{l}\text { False claims about the } \\
\text { origin and severity of the } \\
\text { pandemic }\end{array}$ & $\begin{array}{l}\text { Non-health } \\
\text { misinformation }\end{array}$ & $\begin{array}{l}\text { 'Russia confirms the novel coronavirus is } \\
\text { man-made.' } \\
\text { 'Increased COVID-19 testing makes the } \\
\text { US look bad by increasing coronavirus } \\
\text { case numbers.' } \\
\text { 'The novel coronavirus is going to go } \\
\text { away without a vaccine.' } \\
\text { 'Le scientifique Charles Lieber a été arrêté } \\
\text { pour avoir "'fabriqué et vendu"" le } \\
\text { nouveau coronavirus à la Chine.' }\end{array}$ & $418(11.5 \%)$ \\
\hline 2 & $\begin{array}{l}\text { Inaccurate and } \\
\text { pseudoscientific claims } \\
\text { about the treatment and } \\
\text { vaccine }\end{array}$ & $\begin{array}{l}\text { Health } \\
\text { misinformation }\end{array}$ & $\begin{array}{l}\text { 'Un vaccin contre le coronavirus est prêt.' } \\
\text { 'Bill Gates prognostiziert } 700.000 \text { Opfer } \\
\text { durch Corona-Impfung.' } \\
\text { 'Consuming silver particles kills novel } \\
\text { coronavirus.' }\end{array}$ & $750(20.6 \%)$ \\
\hline 3 & $\begin{array}{l}\text { False or fabricated content } \\
\text { about government's } \\
\text { COVID-responses, } \\
\text { lockdown and curfew } \\
\text { measures. }\end{array}$ & $\begin{array}{l}\text { Non-health } \\
\text { misinformation }\end{array}$ & $\begin{array}{l}\text { 'Italian police arrested a man for breaking } \\
\text { Coronavirus lockdown.' } \\
\text { 'List with dates \& timings for distributions } \\
\text { of essential items in Mumbai during the } \\
\text { curfew due to coronavirus.' } \\
\text { 'Islamic extremists killed a Hindu man in } \\
\text { Rajasthan during COVID-19 lockdown.' } \\
\text { 'Muslims offering namaaz in Patparganj, } \\
\text { Delhi, violating COVID-19 lockdown } \\
\text { rules.' }\end{array}$ & $882(24.3 \%)$ \\
\hline 4 & $\begin{array}{l}\text { False claims related to } \\
\text { educational policies and } \\
\text { children in general }\end{array}$ & $\begin{array}{l}\text { Non-health } \\
\text { misinformation }\end{array}$ & $\begin{array}{l}\text { ‘6月份大学英语四六级考试取消’ } \\
\text { ‘北京某区教委初步确认 } 9 \text { 月1日前不开 } \\
\text { 学’ } \\
\text { 'COVID-19 vaccinations, which have } \\
\text { already killed several youngsters, will be } \\
\text { required before children will be allowed to } \\
\text { return to school.' } \\
\text { 'UNICEF has issued bulletins giving } \\
\text { advice to the public on how to stay healthy } \\
\text { as COVID-19 spreads globally.' }\end{array}$ & $201(5.5 \%)$ \\
\hline 5 & $\begin{array}{l}\text { Political conspiracy theories } \\
\text { or disinformation accusing } \\
\text { specific individuals and } \\
\text { institutions }\end{array}$ & $\begin{array}{l}\text { Non-health } \\
\text { misinformation }\end{array}$ & $\begin{array}{l}\text { 'House Democrats "snuck" into the } \$ 3 \\
\text { trillion coronavirus relief bill a provision } \\
\text { that keeps the House in recess until July } \\
21 . \text { ' } \\
\text { 'Dettol company knew about the } \\
\text { Coronavirus.' } \\
\text { 'A man named Christopher Harrington } \\
\text { was denied a patent in } 2015 \text { for a face }\end{array}$ & $483(13.3 \%)$ \\
\hline
\end{tabular}




\begin{tabular}{|c|c|c|c|c|}
\hline & & & $\begin{array}{l}\text { mask design with the serial number CV19- } \\
\text { N95 because Microsoft co-founder Bill } \\
\text { Gates had filed a similar patent six months } \\
\text { earlier.' } \\
\text { 'The biological lab in Wuhan where the } \\
\text { COVID-19 virus was created was } \\
\text { 'funded' by President Barak Hussein } \\
\text { Obama in } 2015 \text { to the tune of } \$ 3,800,000 \\
\text { American dollars.' }\end{array}$ & \\
\hline 6 & $\begin{array}{l}\text { False claims about COVID- } \\
19 \text { transmission and } \\
\text { prevention methods }\end{array}$ & $\begin{array}{l}\text { Health } \\
\text { misinformation }\end{array}$ & $\begin{array}{l}\text { ‘带呼吸阀的口罩没有防护效果’ } \\
\text { 'The virus can be prevented by gargling } \\
\text { with salt, hot water, and vinegar.' } \\
\text { 'Witch hazel can destroy the novel } \\
\text { coronavirus on skin or surfaces.' }\end{array}$ & $211(5.8 \%)$ \\
\hline 7 & $\begin{array}{l}\text { Inaccurate information } \\
\text { regarding traveling } \\
\text { restrictions }\end{array}$ & $\begin{array}{l}\text { Non-health } \\
\text { misinformation }\end{array}$ & $\begin{array}{l}\text { “韩国来蓉80名韩籍人员仅量体温就放 } \\
\text { 行, 不隔离” } \\
\text { ‘中国驻莫桑比克大使馆通知在莫公民 } \\
\text { 做病毒核酸检测, 为包机回国做必要准 } \\
\text { 备’ } \\
\text { 'India began screening passengers from } \\
\text { COVID-19-affected countries before it } \\
\text { had a single case.' } \\
\text { 'Italy was “hit hard” by the coronavirus } \\
\text { pandemic because “a lot of the people that } \\
\text { didn't come in here went to Italy” when } \\
\text { the US imposed travel restrictions on } \\
\text { China.' }\end{array}$ & $416(11.5 \%)$ \\
\hline 8 & $\begin{array}{l}\text { Incorrect statement and } \\
\text { figures on confirmed cases }\end{array}$ & $\begin{array}{l}\text { Health } \\
\text { misinformation }\end{array}$ & $\begin{array}{l}\text { 'Vergleich: Im Jahr 2017/18 gab es } 25.000 \\
\text { Grippetote und bisher erst } 3000 \text { Corona- } \\
\text { Tot'e } \\
\text { 'Coronavirus in Italien: Keiner ist } \\
\text { gestorben.' } \\
\text { 'The ONS has registered 4,122 deaths in } \\
2020 \text { due to COVID-19.' } \\
\text { “唐山一医院科室因哈尔滨来的患者发 } \\
\text { 烧致全科隔离等待核酸检测’ }\end{array}$ & $272(7.5 \%)$ \\
\hline
\end{tabular}

Note: these examples were extracted from articles with the highest theta.

Figure 2 and Table 3 show the distribution of these eight topics by the top five countries. The left side of the Sankey diagram shows the five countries we studied, and each node is sized by the number of articles from each country. The nodes on the right represent the eight topics, and their size is determined by the number of best-fitted articles.

India contributed most of the articles debunking misinformation about the politicians' and the country's lockdown and curfew measures (topic 3). Misinformation about COVID-19 treatment (topic 2 ) is another prominent misinformation topic for India. For instance, a wide variety of natural remedies to cure COVID-19 can be found in our India dataset, including drinking lemon bicarbonate tea, bitter gourd juice and vinegar.

The topic distribution of France and Germany's infodemic shows a similar pattern. Misinformation circulated and debunked in these two countries covers all eight topics, with a dominance of false claims about politicians and vaccines (topic 3, topic 2). However, unlike India, wherein health misinformation focuses on natural remedies, the misinformation is related more to vaccines in Germany and France .

The US contributed the majority of false claims about the origin and severity of the COVID-19 (topic 1) and COVID-related political conspiracy theories and disinformation (topic 5). Misinformation from the US sub-dataset ranges from claims denying the pandemic to accusations of Democrats about 
distorting the reality of the health crisis, and from theorising China's 'bio-weapon' conspiracies to antivaccination scepticism.

Debunked misinformation in China is most visible on the topics of the state's COVIDresponding policies (topic 4, topic 6) and false medical information about COVID-19 transmission and prevention (topic 7). Interestingly, over half of the Chinese articles are related to false information about travelling restrictions and travellers bringing the virus. In terms of health misinformation, people are often encouraged to take alternative medicines and herbal drinks to prevent COVID-19, and false claims about how the virus is also transmitted frequently appear in the dataset.

When looking at the topics at an aggregated level-health misinformation and non-health misinformation - most of the debunked misinformation is non-health misinformation. The shares of health misinformation in the five countries are: Germany (47.7\%), France (37.1\%), India (29.5\%), the US $(24.2 \%)$ and China (22.5\%). Therefore, except for Germany, the infodemics of the other four countries are predominated by misinformation related to politics and social issues.

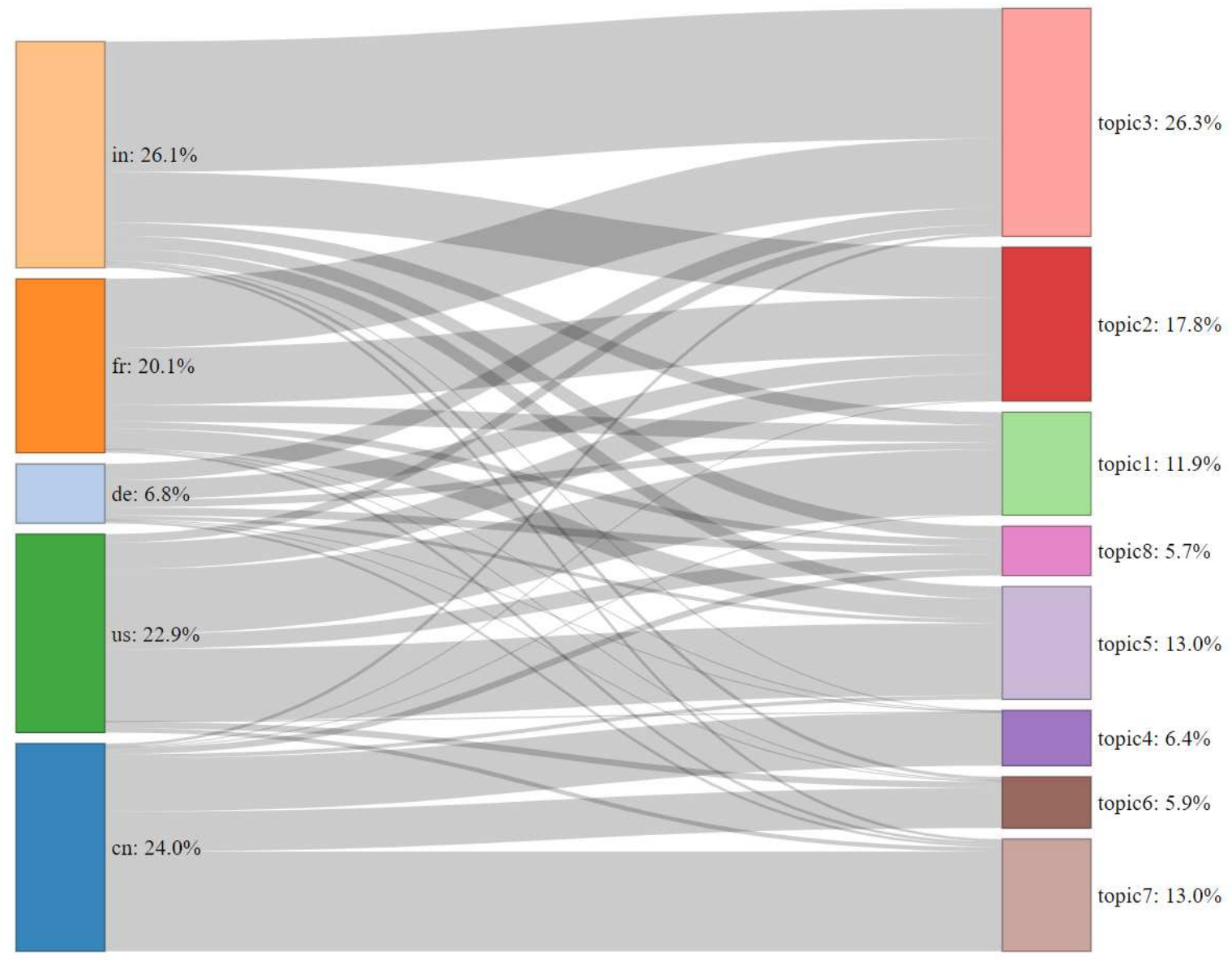

Figure 2: Sankey diagram showing the topic distribution of misinformation in five countries (in: India, fr: France, de: Germany, us: the US, cn: China)

Table 3: Topic distribution in five countries

\begin{tabular}{|c|c|c|c|c|c|c|c|c|}
\hline & $\begin{array}{l}\text { topic } \\
1\end{array}$ & $\begin{array}{l}\text { topic } \\
2\end{array}$ & $\begin{array}{l}\text { topic } \\
3\end{array}$ & $\begin{array}{l}\text { topic } \\
4\end{array}$ & $\begin{array}{l}\text { topic } \\
5\end{array}$ & $\begin{array}{l}\text { topic } \\
6\end{array}$ & $\begin{array}{l}\text { topic } \\
7\end{array}$ & $\begin{array}{l}\text { topic } \\
8\end{array}$ \\
\hline hina & & & & & & & & \\
\hline
\end{tabular}




\begin{tabular}{lcccccccc}
\hline Germany & 27 & 70 & 60 & 2 & 14 & 3 & 9 & 29 \\
\hline France & 61 & 205 & 250 & 1 & 73 & 3 & 10 & 25 \\
\hline India & 47 & 182 & 471 & 3 & 45 & 12 & 10 & 47 \\
\hline US & 234 & 96 & 31 & 1 & 261 & 23 & 16 & 54
\end{tabular}

\section{Temporal distribution}

To study the temporal distribution of the COVID-infodemic, we constructed an epidemic curve and an infodemic curve for each country, from 2020-1-22 to 2020-07-28. The time series are results presented in Figure 3.

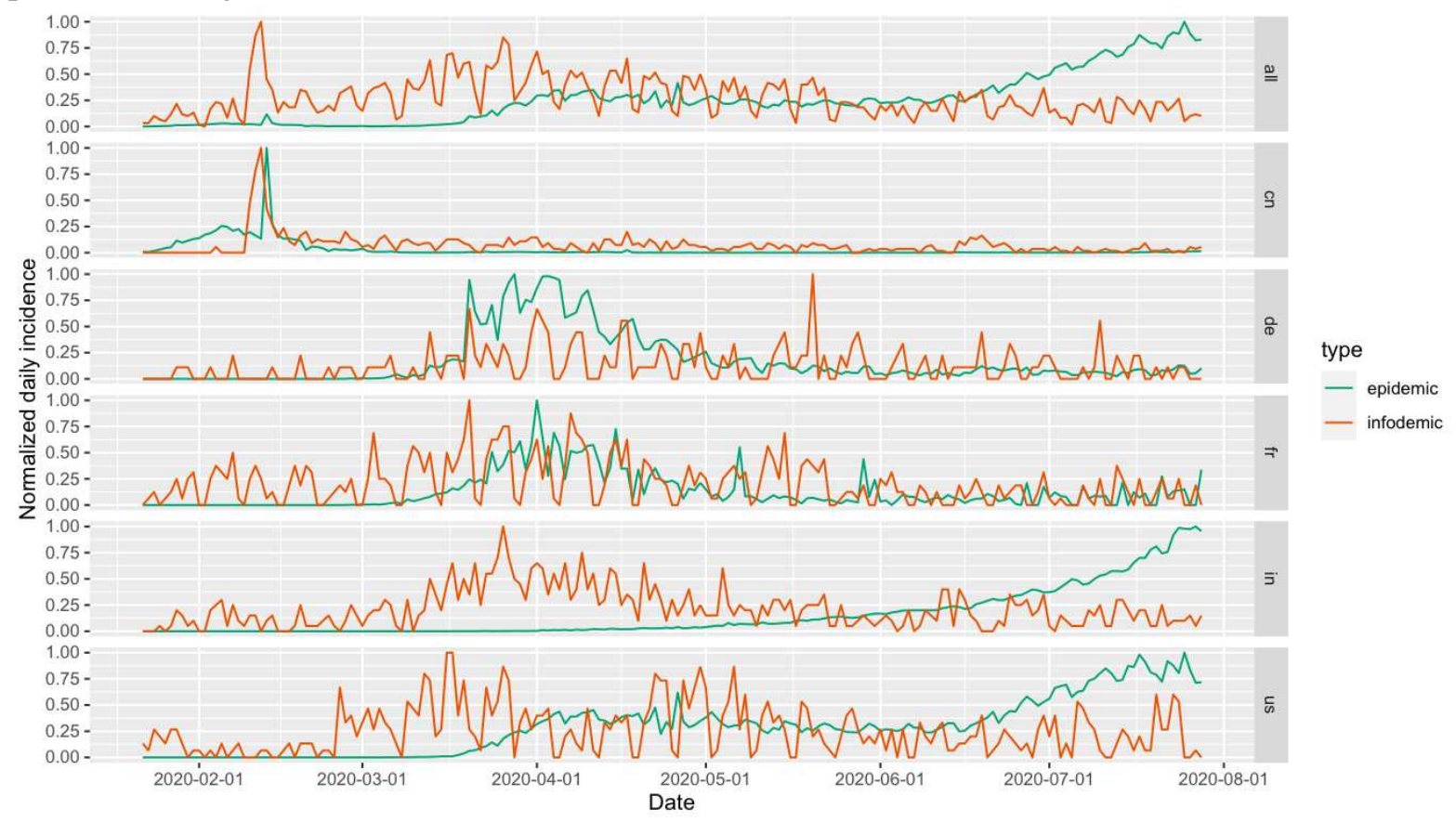

Figure 3: Epidemic and infodemic curves from 2020-1-22 to 2020-07-28 by country (in: India, fr: France, de: Germany, us: U.S., cn: China)

One notable feature from Figure 3 is that the infodemic curves display a 7-day seasonality; to a lesser extent, this is also seen in the epidemic curves. Plotting the autocorrelation function (ACF) of both curves shows a very significant 7-day seasonality (Online Appendix

https://osf.io/sb79w/?view_only=8bd826341c4a440389599384f387b5c5 $)^{6}$. After adjusting for the 7day seasonality, the detected maximum lag orders from the epidemic and infodemic curves are 15 days and 9 days, respectively. The maximum lag order for the epidemic curve ( 15 days) matches the upper limit of the COVID-19 incubation period reported in the medical literature (14.98 days) (Qin $e t$ al., 2020). When both were jointly used, the maximum lag order detected is 10 days. Therefore, in the subsequent analysis, we used VAR (10).

\footnotetext{
${ }^{6}$ As corroborating evidence, this 7-day oscillation pattern has been previously reported in the medical literature (Bukhari, et al., 2020). The German health institution, Robert Koch-Institut, explained this weekly pattern by the decreasing testing capability on Sunday.
} 
The detailed results of these VAR (10) models are available in the Online Appendix. Among these five countries, the US and India models cannot identify any significant temporal relationship between the epidemic and infodemic curves. For Germany and France, a weak relationship was identified. For China, a very strong mutual relationship was identified, i.e. both the epidemic and infodemic curves predict each other.

To demonstrate how the two types of misinformation respond differently to the epidemic curve, we plotted the infodemic curves again by breaking down all the misinformation (Figure 4).

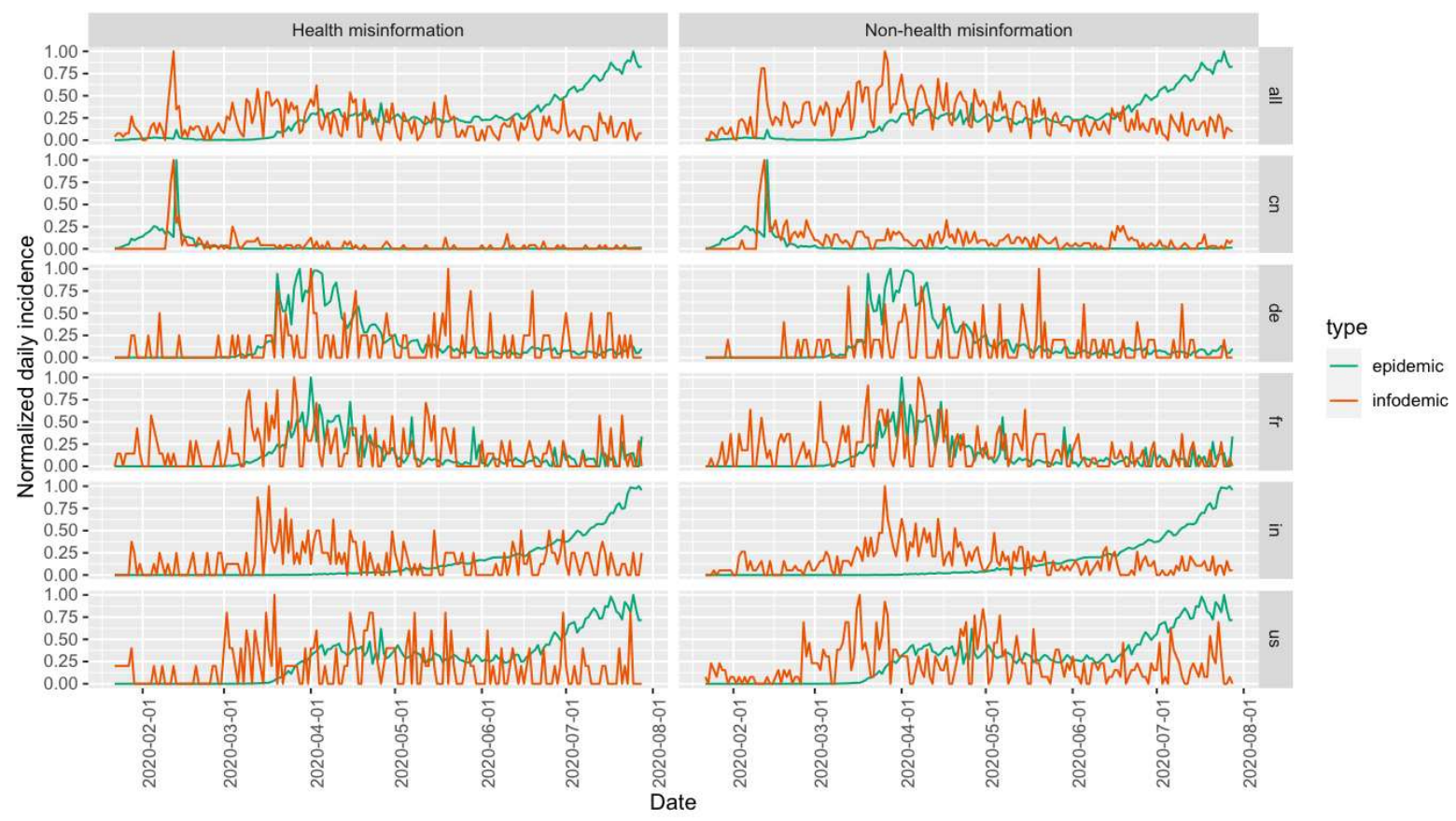

Figure 4: Epidemic and infodemic curves from 2020-1-22 to 2020-07-28 by countries and by topics; left: health misinformation; right: non-health misinformation (in: India, fr: France, de: Germany, us: the US., cn: China)

The medical infodemic curves seem to be tracking better with the epidemic curves in some cases. It is more pronounced in China: the spikes in health misinformation subsided after the initial outbreak, but there were still some small spikes of non-health information in the infodemic curve. However, India and the US did not fit this pattern. The Granger causality test results for all seven models are presented in Table 4 . In all five countries, the causal relationship is strengthened when non-medical misinformation is excluded.

Table 4: Statistical tests for whether the epidemic is a Granger cause of the infodemic: All articles and articles about medical misinformation

\begin{tabular}{lll}
\hline & $\begin{array}{l}\text { Granger: all articles } \\
(\mathbf{F}, \mathbf{d f 1}=\mathbf{1}, \mathbf{d f 2}=\mathbf{3 1 0})\end{array}$ & $\begin{array}{l}\text { Granger: articles about medical misinformation } \\
(\mathbf{F}, \mathbf{d f 1}=\mathbf{1}, \mathbf{d f 2}=\mathbf{3 0 4})\end{array}$ \\
\hline All five countries & 0.772 & 0.573 \\
\hline China & $3.6358^{* * *}$ & $5.2337^{* * *}$ \\
\hline Germany & 1.3874 & $1.9014^{* *}$ \\
\hline France & $1.864^{*}$ & $1.7541^{*}$ \\
\hline India & 0.422 & 0.78966 \\
\hline US & 0.436 & 0.90402 \\
\hline
\end{tabular}


$* \mathrm{p}<0.1 ; * * \mathrm{p}<0.05 ; * * * \mathrm{p}<0.001$

\section{Discussion}

\section{Country-level topical characteristic}

The cross-lingual topic extraction findings reveal the distinguishing patterns of COVID-infodemic in the five countries we researched. In terms of topic distribution, France and Germany share a similar pattern, but quantity-wise Germany has the smallest presence of COVID-misinformation. Moreover, Germany is the only country in this study whose infodemic was not dominated by politically-oriented misinformation during the study period ${ }^{7}$. Germany's resilience to misinformation, especially to politically-driven misinformation, during the pandemic is not surprising. As Humprecht et al. (2020) pointed out, in Western democracies, a country's resistance to misinformation relies on various macrolevel characteristics, such as strong public service broadcasting, high levels of trust in news media and a low level of societal polarisation. Based on Humprecht et al.'s (2020) empirical findings, Germany scores much higher than France and the US in all these areas. Based on the same framework proposed by Humprecht et al.'s (2020), the US is one of the least resilient Western countries when it comes to misinformation. This observation is also supported by our findings. Amongst the three Western democratic countries, the US has the largest prevalence of COVID-related misinformation and over $75 \%$ of it can be considered to be politically driven.

China's COVID-infodemic has been dominated by false information about how the virus is transmitted, how to prevent it and rumours about travelling and travellers amid the outbreak. As the country where the outbreak began, the level of uncertainty around how the new virus is transmitted and how to prevent the transmission has been naturally much higher in China than in other countries. This may explain the prevalence of false information under this topic. As previously mentioned, over half of China's debunked rumours are related to travel restrictions and people arriving from other regions. The dominance of this topic could be explained by the fact that the outbreak coincided with China's massive yearly migration of people during the spring festival, as well as by certain regions' draconian lockdown and quarantine policies. For instance, some of the fabricated information that frequently appeared included stories about spring festival returnees bringing the virus back to their hometown and foreign visitors not following the quarantine rules.

One distinctive feature of India's infodemic is the high prevalence of wedge-driving rumours against the country's Muslim population. As previously explained, wedge-driving rumours operate to undermine outgroups, strengthening prejudicial attitudes against them (Knapp, 1944). As our topic model suggests, over $70 \%$ of the articles from India are labelled as non-health misinformation, of which the most visible topic is the country's lockdown and curfew policies. However, a large amount of misinformation related to this topic targets Muslims. For instance, some recurring fabricated stories contain titles, such as 'Muslims offering namaaz in Patparganj, Delhi, violating COVID-19 lockdown rules', 'Muslims deliberately spread coronavirus during lockdown', and 'Islamic extremists killed a Hindu man in Rajasthan during COVID-19 lockdown'. These wedge-driving rumours have their roots in the long-standing religious tension between India's Hindu nationalists and Muslim communities. Furthermore, similar to China, pseudoscientific remedies against COVID-19 are featured prominently in India's infodemic.

\footnotetext{
${ }^{7}$ German political misinformation does exist in our corpus. The study by Boberg et al. (2020) attributed the political misinformation on German Facebook to alternative media news media. Many of these alternative media are either operated in foreign countries (e.g. Spuntik Deutschland and RT Deutsch) or by ring-wing bloggers (e.g. Achse des Guten).
} 


\section{Temporal variation: Hybrid infodemic}

Our discussion demonstrates that misinformation, driven by social and political factors, has been highly visible during the COVID-infodemic in all five of the countries we studied. Findings from the time series analysis further illustrate how health misinformation and non-health misinformation evolve differently against the epidemic curve.

Our time series analysis shows that the current COVID-infodemic is a hybrid of two infodemics. Borrowing the language of epidemiology, we call them the point-source infodemic (PSI) and the continuous infodemic (CI).

In a PSI, misinformation is a direct by-product of the epidemic; thus, the epidemic is a Granger cause of the infodemic. Similarly, the topics of misinformation are more directly related to the scientific aspects of the COVID-epidemic. When it comes to the temporal distribution, this form of infodemic shares the same pattern as a point-source epidemic: the infodemic correlates strongly with the development of the common causal agent (COVID). Using a health-related weather analogy, with a terrible heatwave (COVID) comes an epidemic of heat stroke (PSI). Based on our findings on the countries' infodemic temporal distribution, France, Germany and China can be diagnosed as PSI countries.

However, in a CI, the COVID-epidemic provides an opportunity to stir existing social and political tensions. This kind of infodemic is relatively disconnected from the development of the epidemic. Regarding its temporal distribution, this form of infodemic shares the same pattern as a continuous epidemic: the causal agent is a continuous external source, so the infodemic does not correlate with the COVID epidemic. Using a similar health-related weather analogy, a continuous contaminated water source (non-COVID continuous source) is causing an outbreak of cholera (CI) because a heatwave (COVID) is compelling people to drink more contaminated water. The heatwave (COVID) is the reason why people drink more contaminated water. India and the US can be diagnosed as $\mathrm{CI}$ countries.

In India, we can observe both types of infodemics in action in March (Figure 3). In early-tomid-March, PSI was relatively more rampant, probably because it followed the emerging epidemic in Europe. However, in mid-to-late March, CI kicked in; this could be explained by the Prime Minister's introduction of a self-imposed curfew and a 21-day lockdown (Reuters, 2020). Moreover, in the same month, the Tablighi Jamaat - an Indian Islamic organisation - was reported to be linked to over 400 COVID-19 cases in the country (Slater et al., 2020). This community outbreak provoked a spate of antiMuslim sentiment in India, as well as a surge of Islamophobic misinformation.

In the US, COVID-related misinformation was rampant after the start of the outbreak. To use epidemiological terminology, in the US the infodemic resembles an endemic (the incidence of the disease is maintained at a relatively stable level). This endemic-like infodemic (or 'enfodemic') indicates that misinformation in the US is a feature that is always in the country and is not a direct byproduct of the epidemic. Instead, it mirrors the country's existing socio-political issues, such as political polarisation and social inequality. Public health measures, such as a lockdown, can quickly become a bipartisan issue. Both health and non-health misinformation kicked in after the epidemic curve started to flatten due to the lockdown. When the second wave of COVID-19 hit in June, misinformation was maintained at a constant, but alarming level.

In the existing literature, the communication pattern of misinformation is often analysed as a general and single item (e.g. Bessi et al., 2015; Del Vicario et al., 2016). Similar trends can also be observed in recent studies on the COVID-infodemic (Cinelli et al., 2020; Zarocostas, 2020). In contrast, we demonstrated how two forms of COVID-misinformation can be distinguished theoretically and empirically. However, as we have acknowledged, our binary categorisation is a streamlined attempt to computationally study COVID-infodemic in a multilingual context. Future research should aim to introduce more nuance when analysing how misinformation develops. Furthermore, diagnosing and 
differentiating these two types of infodemics is only the first step. Future research should continue to test how counterstrategies against point-source and continuous epidemics can be also applied to develop mitigation measures in an infodemic.

\section{Conclusion}

Using a cross-national and cross-lingual perspective, the study presented in this paper has demonstrated how the COVID-infodemic unfolds differently in China, India, France, Germany and the US. By analysing 3633 fact-checked articles, this study explored the particularities in the infodemics in these five countries. With an emphasis on the COVID-infodemic's topical and temporal development, this study employed rectr - an aligned word embedding-based topic extraction algorithm — and a time series analysis. The cross-lingual topic model findings reveal the topical characteristics of each country. Furthermore, on an aggregated level, health misinformation represents only a small portion of the COVID-infodemic. The time series results indicate that, for most of the studied countries, the infodemic curve fluctuates with the epidemic curve. In this study, we labelled this form of infodemic as a pointsource infodemic. The second type of infodemic this study diagnosed was labelled as a continuous infodemic, which was seen in the cases of India and the US. In India and the US, the infodemic is predominantly caused by political misinformation, and its temporal distribution appears to be largely unrelated to the epidemic development.

Communication surveillance, especially related to misinformation, is becoming increasingly important for public health surveillance, and it has attracted a growing body of academic research (Fu and Zhu, 2020; Fung et al. 2013; Chou et al., 2018). This study introduced an innovative approach to conduct a cross-lingual analysis of misinformation around a global health crisis. Even though the current study only reviewed studies written in Chinese, English, German and French, future research should apply the same approach to conduct a cross-lingual content analysis of misinformation in many more languages. Furthermore, future research should also try to expand the scope of comparative research agenda on the COVID-infodemic by investigating more communication dimensions. As previously mentioned, this study examines exclusively the topical and temporal features of misinformation during the pandemic, but it is also important to understand how the dynamic of regional infodemic varies on the actor and technological levels. For instance, it is worth asking how varied forms of actors and technologies are involved in propagating misinformation in different regions.

\section{References}

Abidin, C., \& Zeng, J. (2020). Feeling Asian Together: Coping With\# COVIDRacism on Subtle Asian Traits. Social Media+Society. DOI: 10.1177/2056305120948223

Allgaier, J., \& Svalastog, A. L. (2015). The communication aspects of the Ebola virus disease outbreak in Western Africa-do we need to counter one, two, or many epidemics?. Croatian Medical Journal, 56(5), 496.

Allport, G. W., and Postman, L. (1947). The psychology of rumor. New York: Holt, Rinehart \& Winston.

Arif, A., Shanahan, K., Chou, F.J., Dosouto, Y., Starbird, K., and Spiro, E. S. (2016). How Information Snowballs: Exploring the Role of Exposure in Online Rumor Propagation. In Proceedings of the 19th ACM Conference on Computer-Supported Cooperative Work \& Social Computing (pp. 466-477): ACM.

Bessi, A., Coletto, M., Davidescu, G. A., Scala, A., Caldarelli, G., \& Quattrociocchi, W. (2015). Science vs conspiracy: Collective narratives in the age of misinformation. PloS one, 10(2). DOI: 10.1371/journal.pone.0118093

Boberg, S., Quandt, T., Schatto-Eckrodt, T., \& Frischlich, L. (2020). Pandemic populism: Facebook pages of alternative news media and the corona crisis--A computational content analysis. arXiv preprint arXiv:2004.02566. 
Brennen, J. S., Simon, F., Howard, P. N., \& Nielsen, R. K. (2020). Types, sources, and claims of Covid-19 misinformation. Reuters Institute, 7, 3-1.

Bruns, A., Harrington, S., \& Hurcombe, E. (2020). 'Corona? 5G? or both?': the dynamics of COVID19/5G conspiracy theories on Facebook. Media International Australia. $10.1177 / 1329878 X 20946113$

Bukhari, Q., Jameel, Y., Massaro, J. M., D’Agostino, R. B., \& Khan, S. (2020). Periodic Oscillations in Daily Reported Infections and Deaths for Coronavirus Disease 2019. JAMA network open, 3(8), e2017521-e2017521.

Chan, C. H., Zeng, J., Wessler, H., Jungblut, M., Welbers, K., Bajjalieh, J. W., van Atteveldt, W. \& Althaus, S. L. (2020). Reproducible Extraction of Cross-lingual Topics (rectr). Communication Methods and Measures, 1-21.DOI: 10.1080/19312458.2020.1812555

Chou, W. Y. S., Oh, A., \& Klein, W. M. (2018). Addressing health-related misinformation on social media. Jama, 320(23), 2417-2418. doi:10.1001/jama.2018.16865

Cinelli, M., Quattrociocchi, W., Galeazzi, A., Valensise, C. M., Brugnoli, E., Schmidt, A. L., ... \& Scala, A. (2020). The covid-19 social media infodemic. arXiv preprint arXiv:2003.05004

Dale, D. (2020, September 2). Fact check: A guide to 9 conspiracy theories Trump is currently pushing. CNN Facts Firsts. Available a thttps://edition.cnn.com/2020/09/02/politics/fact-checktrump-conspiracy-theories-biden-covid-thugs-plane/index.html

Del Vicario, M., Bessi, A., Zollo, F., Petroni, F., Scala, A., Caldarelli, G., ... \& Quattrociocchi, W. (2016). The spreading of misinformation online. Proceedings of the National Academy of Sciences, 113(3), 554-559. doi: 10.1073/pnas.1517441113

DiFonzo, N., and Bordia, P. (2007). Rumor, gossip and urban legends. Diogenes, 54(1), 19-35.

Dredze, M., Broniatowski, D. A., \& Hilyard, K. M. (2016). Zika vaccine misconceptions: A social media analysis. Vaccine, 34(30), 3441. doi: 10.1016/j.vaccine.2016.05.008

Elhadad, M. K., Li, K. F., \& Gebali, F. (2020, August). COVID-19-FAKES: a Twitter (Arabic/English) dataset for detecting misleading information on COVID-19. In International Conference on Intelligent Networking and Collaborative Systems (pp. 256-268). Springer, Cham.

Foucault, M. (1980). Power/knowledge: Selected interviews and other writings, 1972-1977. New York: Pantheon.

Fu, K. W., \& Zhu, Y. (2020). Did the world overlook the media's early warning of COVID-19?. Journal of Risk Research, 1-5. doi:10.1080/13669877.2020.1756380

Fung, I. C. H., Fu, K. W., Chan, C. H., Chan, B. S. B., Cheung, C. N., Abraham, T., \& Tse, Z. T. H. (2016). Social media's initial reaction to information and misinformation on Ebola, August 2014: facts and rumors. Public Health Reports, 131(3), 461-473. doi: $10.1177 / 003335491613100312$

Fung, I. C. H., Zeng, J., Chan, C. H., Liang, H., Yin, J., Liu, Z., ... \& Fu, K. W. (2018). Twitter and Middle East respiratory syndrome, South Korea, 2015: A multi-lingual study. Infection, Disease \& Health, 23(1), 10-16. doi: 10.1016/j.idh.2017.08.005

Gray, M. (2008). Explaining conspiracy theories in modern Arab Middle Eastern political discourse: some problems and limitations of the literature. Critique: Critical Middle Eastern Studies, 17(2): 155-174. doi: 10.1080/10669920802172353

Guess, A. M., \& Lyons, B. A. (2020). Misinformation, Disinformation, and Online Propaganda. In Persily, N., \& Tucker, J. A. (Eds.) Social Media and Democracy: The State of the Field, Prospects for Reform. Cambridge: Cambridge University Press.10-33.

Herek, G. M., Capitanio, J. P., \& Widaman, K. F. (2002). HIV-related stigma and knowledge in the United States: prevalence and trends, 1991-1999. American journal of public health, 92(3), 371-377. doi: 10.2105/AJPH.92.3.371

Humprecht, E., Esser, F., \& Van Aelst, P. (2020). Resilience to online disinformation: A framework for cross-national comparative research. The International Journal of Press/Politics, 25(3), 493-516. doi: 10.1177/1940161219900126

Karlova, N. A., \& Fisher, K. E. (2013). A social diffusion model of misinformation and disinformation for understanding human information behaviour. Available at http://informationr.net/ir/18-1/paper573.html\#.X2FBNpMzaPc 
Kata, A. (2012). Anti-vaccine activists, Web 2.0, and the postmodern paradigm-An overview of tactics and tropes used online by the anti-vaccination movement. Vaccine, 30(25), 3778-3789. doi: 10.1016/j.vaccine.2011.11.112

Knapp, R. H. (1944). A psychology of rumor. Public opinion quarterly, 8(1), 22-37. doi: $10.1086 / 265665$

Lewandowsky, S., Stritzke, W. G. K., Freund, A. M, Oberauer, K., and Krueger, J. I. (2013). Misinformation, disinformation, and violent conflict: From Iraq and the 'War on Terror' to future threats to peace. American Psychologist, 68(7), 487.

Maier, D., Waldherr, A., Miltner, P., Wiedemann, G., Niekler, A., Keinert, A., Pfetsch, B., Heyer, G., Reber, U., Häussler, T., Schmid-Petri, H. \& Schmid-Petri, H. (2018). Applying LDA topic modeling in communication research: Toward a valid and reliable methodology. Communication Methods and Measures, 12(2-3), 93-118. doi: $10.1080 / 19312458.2018 .1430754$

Marwick, A., \& Lewis, R. (2017). Media manipulation and disinformation online. New York: Data \& Society Research Institute.

Newbrun, E. (1996). The fluoridation war: a scientific dispute or a religious argument?. Journal of public health dentistry, 56(5), 246-252. doi: 10.1111/j.1752-7325.1996.tb02447.x

Oyeyemi, S. O., Gabarron, E., \& Wynn, R. (2014). Ebola, Twitter, and misinformation: a dangerous combination? Bmj, 349. doi: 10.1136/bmj.g6178

Parker, R. M., Ratzan, S. C., \& Lurie, N. (2003). Health literacy: A policy challenge for advancing high-quality health care. Health Affairs, 22, 147-153. doi:10.1377/hlthaff.22.4.147

Pfaff, B. (2008). VAR, SVAR and SVEC models: Implementation within R package vars. Journal of Statistical Software, 27(4), 1-32. doi: 10.18637/jss.v027.i04

Qin, J., You, C., Lin, Q., Hu, T., Yu, S., \& Zhou, X. H. (2020). Estimation of incubation period distribution of COVID-19 using disease onset forward time: a novel cross-sectional and forward follow-up study. medRxiv.

Reuters (2020, March 24). Modi puts all of India under lockdown for 21 days to fight coronavirus. Available at https://www.reuters.com/article/us-health-coronavirus-india-modiidUSKBN21B2BW

Ritchie, H. (2020). Coronavirus Source Data. Our World in Data. Available at https://ourworldindata.org/coronavirus-source-data

Rojecki, A., and Meraz, S. (2016). Rumors and factitious informational blends: The role of the web in speculative politics. New Media \& Society, 18(1), 25-43. doi: 10.1177/1461444814535724

Rosenberg, P. S. (2014). Epidemic curve. Wiley StatsRef: Statistics Reference Online.

Ross, A. S., \& Rivers, D. J. (2018). Discursive deflection: Accusation of "fake news" and the spread of mis-and disinformation in the tweets of President Trump. Social Media+ Society, 4(2), 2056305118776010. doi: 2056305118776010

Sardarizadeh, S. and Robinson, O. (2020, April 26) Coronavirus: US and China trade conspiracy theories. BBC News. Available at https://www.bbc.com/news/world-52224331

Shahi, G. K., \& Nandini, D. (2020). FakeCovid--A Multilingual Cross-domain Fact Check News Dataset for COVID-19. arXiv preprint arXiv:2006.11343.

Shibutani, T. (1966). Improvised news: A sociological study of rumor. London: Ardent Media.

Slater, J., Masih, N., and Irfan, S. (2020, April 2) India confronts its first coronavirus 'superspreader'. The Washington Post. Available at https://www.washingtonpost.com/world/asia_pacific/india-coronavirus-tablighi-jamaatdelhi/2020/04/02/abdc5af0-7386-11ea-ad9b-254ec99993bc_story.html

Smith, G. D., Ng, F., \& Li, W. H. C. (2020). COVID-19: Emerging compassion, courage and resilience in the face of misinformation and adversity. Journal of Clinical Nursing, 29(9-10), 1425. doi: 10.1111 jocn. 15231

Spring, M. (2020, May 27) Coronavirus: The human cost of virus misinformation. BBC News. Available at https://www.bbc.com/news/stories-52731624

United Nations (2020, Mar 28). UN tackles 'infodemic' of misinformation and cybercrime in COVID-19 crisis. https://www.un.org/en/un-coronavirus-communications-team/un-tackling'infodemic'-misinformation-and-cybercrime-covid-19 
Uscinski, J. (2019). What do conspiracy theories look like around the world ? In Uscinski, J. (Ed) Conspiracy Theories \& the People Who Believe Them. New York: Oxford University Press (pp. 335-336).

Wardle, C., \& Derakhshan, H. (2017). Information disorder: Toward an interdisciplinary framework for research and policy making. Council of Europe report, 27.

Wells, C., Shah, D. V., Pevehouse, J. C., Foley, J., Lukito, J., Pelled, A., \& Yang, J. (2019). The Temporal Turn in Communication Research: Time Series Analyses Using Computational Approaches. International Journal of Communication (19328036), 13.

Wood, M. J. (2018). Propagating and debunking conspiracy theories on Twitter during the 2015-2016 Zika virus outbreak. Cyberpsychology, Behavior, and Social Networking 21(8), 485-490. doi: 10.1089/cyber.2017.0669

Yang, F., Liu, Y., Yu, X., \& Yang, M. (2012, August). Automatic detection of rumor on sina weibo. In Proceedings of the ACM SIGKDD workshop on mining data semantics (pp. 1-7).

Zarocostas, J. (2020). How to fight an infodemic. The Lancet, 395(10225), 676.

Zeng, J., Chan, C. H., \& Fu, K. W. (2017). How Social Media Construct "Truth" Around Crisis Events: Weibo's Rumor Management Strategies After the 2015 Tianjin Blasts. Policy \& Internet, 9(3), 297-320. doi: 10.1002/poi3.155

Zeng, J. (forthcoming). Theoretical typology of deceptive content. In Oehmer, F., Kessler, S. H., Humprecht, E., Sommer, K., \& Castro Herrero, L. (Eds). Database of Categories for Content Analysis. Zürich: Hope.

Zhang, D., Mei, Q., \& Zhai, C. (2010, July). Cross-lingual latent topic extraction. In Proceedings of the 48th annual meeting of the association for computational linguistics (pp. 1128-1137). Association for Computational Linguistics. http://sci-hub.tw/10.5555/1858681.1858796 